\title{
Types of Degree Questions: Consequences of Different Adjective Classes
}

\author{
Katy McKinney-Bock \\ University of Southern California \\ ksmckinn@usc.edu
}

\subsection{Introduction}

This paper observes that what constitutes an appropriate answer to a degree question differs for two types of gradable adjectives - dimension (e.g. big) and color (e.g. red) adjectives. Before setting out an analysis of degree questions, I look to independent semantic differences between dimension and color adjectives. I propose that dimension adjectives merge with a DEG degree head that takes a for-phrase as its restrictor, and a POS degree head (von Stechow 1984); color adjectives merge directly with POS. This key difference between big and red is also manifested in degree questions, where how merges instead of POS (following Sæbø 2010).

\subsection{Empirical Observation}

The answer to a color degree question (CDQ) requires overt degree modification of the same color adjective (iia,b vs. iic-e), while an answer to a dimension degree question (DDQ) does not (ia,b).

(i) Dimension Degree Question:

How big (of) a car did Mary buy?
(a) A big car
(b) A small car
(c) A very big car
(d) A not very big car

(ii) Color Degree Question:

How red (of) a car did Mary buy?
(a) \#A red car
(b) \#A yellow car
(c) A very red car
(d) A not very red car
(e) A dark red car

I argue that this difference comes from an inherent difference of the adjectives themselves, shown by the following properties. First, dimension adjectives are interpreted with respect to a comparison class, while color adjectives lack a comparison class.

(2) (a) big for a car

(b) \#red for a strawberry

Second, dimension adjectives have an antonym, (3a), while color adjectives do not have a clear antonym, (3b). These properties of the dimension and color adjective classes are what underlies the restricted answerhood conditions of CDQ compared to DDQ.
(3)
(a) $\mathrm{big} / \mathrm{small}$
(b) $\mathrm{red} / ?$
(Kennedy 1999, 2007, a.o.) 


\subsection{Difference between color and dimension adjectives}

Using an interval semantics (Schwarzschild \& Wilkinson 2002), I assume that both dimension and color adjectives are of type $\langle<\mathrm{d}, \mathrm{t}\rangle,<\mathrm{e}, \mathrm{t}\rangle>$, and that a POS-operator binds the interval variable in the positive form (von Stechow 1984, a.o.).

$$
\begin{aligned}
& \llbracket \text { big } \rrbracket=\lambda D_{<\mathrm{d}, \downarrow\rangle} . \lambda x . x \text { 's size } \in \mathrm{D} \\
& \llbracket \text { red } \rrbracket=\lambda \mathrm{D}_{<\mathrm{d}, \downarrow>} . \lambda \mathrm{x} . \mathrm{x}^{\prime} \text { s redness } \in \mathrm{D}
\end{aligned}
$$

Inspired by Sæbø 2010, I propose that the POS head for degree adjectives is in fact comprised of two heads. The lower head (DEG) combines with a non-overt for-phrase and the dimension adjective, establishing that the size interval for the individual argument of the adjective is within the comparison class set by the for-phrase. The higher head (POS) sets the positive direction of the scale associated with the adjective. Then, the for-phrase is resolved through ellipsis under identity with the head noun. On the other hand, color adjectives merge directly with the POS head, without DEG, and this combination accounts for why color adjectives are not dependent on a comparison class.

Taking the denotation of big to be (4), the analysis proceeds as follows. A degree head DEG composes with a for-phrase that sets the comparison class, and then big composes with $\mathrm{DEG}+$ forphrase. This puts the size interval for $x$ within the comparison class interval. $S$ is a function that sets the standard interval.

$$
\begin{aligned}
& \llbracket D E G \rrbracket=\lambda \mathrm{P}_{<\mathrm{e}, \mathrm{t}} \cdot \lambda \mathrm{G}_{<\mathrm{dt}, \mathrm{et}} . \lambda \mathrm{D}_{<\mathrm{d}, \mathrm{t}} . \lambda \mathrm{x}: \mathrm{P}(\mathrm{x}) . \exists \mathrm{D}^{\prime}\left[\mathrm{G}\left(\mathrm{D}^{\prime}\right)(\mathrm{x}) \wedge \mathrm{D}^{\prime} \subseteq \mathrm{D} \wedge \mathrm{D} \subseteq \mathrm{S}_{(\mathrm{P}, \mathrm{c})}(\mathrm{G})\right] \\
& \llbracket \text { for a house } \rrbracket=\lambda x \text {. } \mathrm{x} \text { is a house } \quad \text { (e.g., Kennedy 2007, Bale 2008, Schwarz 2010) }{ }^{1}
\end{aligned}
$$

Then, a second degree head POS introduces the standard of comparison (the standard degree of size), and the positive measurement. $S^{\prime}$ is a function that sets the standard degree.

$$
\llbracket P O S \rrbracket=\lambda \mathrm{H}_{<\mathrm{dt}, \mathrm{et}>} . \lambda \mathrm{x} . \exists \mathrm{D}^{\prime \prime}\left[\mathrm{H}\left(\mathrm{D}^{\prime \prime}\right)(\mathrm{x}) \wedge \forall \mathrm{d}\left[\mathrm{d} \in \mathrm{D}^{\prime \prime} \rightarrow \mathrm{d}>\mathrm{S}_{(\mathrm{c})}^{\prime}(\mathrm{H})\right]\right]
$$

$\llbracket$ POS DEG for a house big $\rrbracket=\lambda x$ : house $(\mathrm{x}) . \exists \mathrm{D}^{\prime \prime} \exists \mathrm{D}^{\prime}\left[\left[\operatorname{big}\left(\mathrm{D}^{\prime}\right)(\mathrm{x}) \wedge \mathrm{D}^{\prime} \subseteq \mathrm{D}^{\prime \prime} \wedge\right.\right.$ $\mathrm{D}^{\prime \prime} \subseteq \mathrm{S}_{(\text {house, },(\mathrm{G})}(\mathrm{G}) \wedge \forall \mathrm{d}\left[\mathrm{d} \in \mathrm{D}^{\prime \prime} \rightarrow \mathrm{d}>\mathrm{S}_{(\mathrm{c})}^{\prime}(\right.$ big $\left.\left.)\right]\right]$

there is an interval $D^{\prime}$ such that x's size is in $D^{\prime}$, and $D^{\prime}$ is within some interval $D^{\prime \prime}$ that falls within a contextually salient comparison class for houses, and whose degrees are all greater than the standard degree for a house's size.

If the constituent [POS [big [DEG for an $N$ ]] is left here, the derivation would crash - under the assumption that the ellipsis site must not be c-commanded by its 'antecedent', or, perhaps better said here, its pronounced copy (Sag 1976, Williams 1977). So, for purposes of moving the ellipsis site outside of the scope of the head noun, the entire phrase raises, pied piping big to a position higher than that of red. (cf. similar to approaches to resolving ACD). Then, the for-phrase is elided:

\footnotetext{
${ }^{1}$ These authors propose that the for-phrase merges directly with the adjective, which contrasts with the current proposal.
} 
(9)

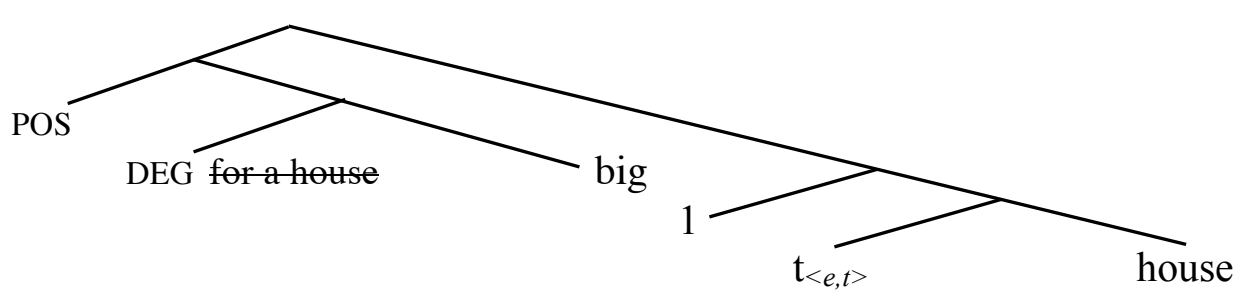

Color adjectives compose directly with POS, and do not merge with DEG.

$$
\llbracket \text { POS red } \rrbracket=\lambda \mathrm{x} . \exists \mathrm{D}^{\prime \prime}\left[\mathrm{x} \text { 's redness } \in \mathrm{D}^{\prime \prime} \wedge \forall \mathrm{d}\left[\mathrm{d} \in \mathrm{D}^{\prime \prime} \rightarrow \mathrm{d}>\mathrm{S}_{(\mathrm{c})}^{\prime}(\text { red })\right]\right]
$$

An immediate question that arises is what prevents DEG from merging with a color adjective, or POS from merging directly with a dimension adjective. To address the former, if DEG merges with red, (and then POS merges too), there is an issue of triviality. Since any comparison class interval will be above the standard ( 0 for $r e d$ ), DEG alone will say that the house's redness is above 0 , so there's no further contribution by POS. The standard degree for red is 0 , as it is a lower-bounded scale (Kennedy 2007). To address the latter, if POS merges directly with big, there is no way to set the standard degree, because the for-phrase is missing and the comparison class interval has not been set - so this is uninterpretable.

\subsection{Difference between Color and Dimension Degree Questions}

The difference between CDQ and DDQ is obtained from the existence of DEG with dimension adjectives, and the lack of DEG with color adjectives. I use a Karttunen semantics for questions. A question quantifier, how, rather than a degree head, POS, quantifies over the degrees as given in (11). The tree in (12) represents the structure:

$$
\llbracket \text { how } \rrbracket=\lambda \mathrm{Q}_{<\mathrm{dt},<\mathrm{st}, \gg>.} \lambda \mathrm{p} . \exists \mathrm{D}^{\prime \prime \prime} \wedge \mathrm{D}^{\prime \prime \prime} \in(0,+\infty) \wedge \mathrm{p}\left(\mathrm{w}^{\circledR}\right) \wedge \mathrm{p} \in \mathrm{Q}\left(\mathrm{D}^{\prime \prime \prime}\right)
$$

$\lambda$ p. $\exists \mathrm{D}^{\prime \prime \prime} \wedge \mathrm{D}^{\prime \prime \prime} \in(0,+\infty) \wedge \mathrm{p}\left(\mathrm{w}^{\circledR}\right) \wedge \mathrm{p} \in\{\lambda \mathrm{w}$. Mary bought a house, whose size in $\mathrm{D}^{\prime \prime \prime}$ is within $\mathrm{D}$ and $\mathrm{D}$ is within a comparison class interval for houses in $\left.\mathrm{w}\right\}$

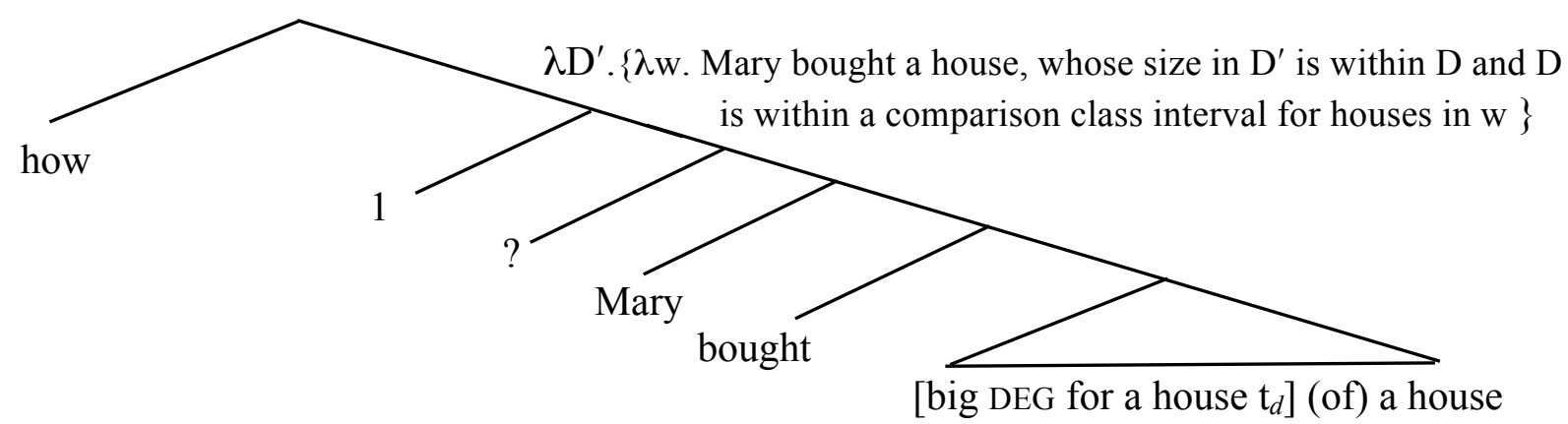

(13) what interval $D^{\prime \prime \prime}$, where $D^{\prime \prime \prime}$ is within a contextually salient comparison class interval for houses, is such that Mary bought a house whose size was $D^{\prime \prime \prime}$ ? 


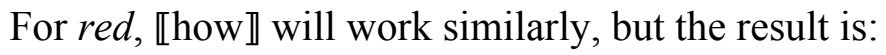

$$
\begin{aligned}
& =\lambda p . \exists \mathrm{D}^{\prime \prime \prime} \wedge \mathrm{D}^{\prime \prime \prime} \in(0,+\infty) \wedge \mathrm{p}\left(\mathrm{w}^{@}\right) \wedge \mathrm{p} \in\left\{\lambda \mathrm{w} \text {. Mary bought a house whose redness is } \mathrm{D}^{\prime \prime \prime}\right. \text { in } \\
& \text { w }\}
\end{aligned}
$$

$$
\text { what interval } D^{\prime \prime \prime} \text { is such that Mary bought a house whose redness was } D^{\prime \prime \prime} \text { ? }
$$

This restricts the answerhood conditions for red to some interval of redness, and the answerhood conditions for big to the intervals that exist within the scale for size (i.e. the degrees that are defined as existing within the comparison class interval). Following the usual analysis for degree questions, a maximal informativity condition selects the maximally informative answer from the answer set (Beck and Rullmann 1996, Abrusán \& Spector 2010, a.o.). For the case of red, that will be the maximal interval of redness. For the case of big, that will be the maximal interval of size within the comparison class.

\subsection{Returning to the Empirical Observation}

This analysis accounts for $(1 \mathrm{i}, \mathrm{a}) /(1 \mathrm{i}, \mathrm{b})$ because it indicates that the value meets or exceeds the standard of SIZE for a car, within the comparison class for cars, and so belongs to the set of possible answers. $(1 \mathrm{i}, \mathrm{c} ; 1 \mathrm{i}, \mathrm{d})$ contain the equivalent necessary information as $(1 \mathrm{i}, \mathrm{a})$, so their acceptability follows. $(2 \mathrm{i}, \mathrm{a})$ is unacceptable as it only asserts that the object has some degree of redness that is greater than zero. This is a trivial answer, as the question quantifier has already restricted the domain to precisely these degrees. $(2 \mathrm{i}, \mathrm{b})$ is unacceptable because it indicates that the object has a value of redness that is zero, while the semantics of the question restricts the relevant degree to fall within the scale for redness. $(2 \mathrm{i}, \mathrm{c}-\mathrm{e})$ contain a degree modifier that indicates the degree of redness for the object on a scale of redness and so belong to the answer set.

\subsection{Conclusion}

When we ask how big an object is, we are asking for its size within some reasonable limits given its comparison class. When we ask how red, we are asking what degree of redness the object has. This difference is accounted for by the presence of an additional degree head DEG with big, and its absence with red.

\section{Selected References}

Abrusán, M. \& B. Spector. 2010. A Semantics for Degree Questions Based on Intervals: Negative Islands and their Obviation. Journal of Semantics. Beck, S. \& H. Rullman. 1996. Proceedings of the Tenth Amsterdam Colloquium. eds. P. Dekker \& M. Stokhof. ILLC, University of Amsterdam. 73-92. Heim, I. 2000. Degree Operators and Scope. in Proceedings of SALT X, Cornell University. 40-64. Karttunen, L. 1977. Syntax and semantics of questions. Linguistics and Philosophy 1.1. 3-44. Kennedy, C. 1999. Gradable Adjectives Denote Measure Functions, Not Partial Functions. Studies in the Linguistic Sciences 29.1. Kennedy, C. 2007. Vagueness and grammar: the semantics of relative and absolute gradable adjectives. Linguistics and Philosophy. Sabo, K.J. 2010. On the Semantics of Embedded Exclamatives. Studia Linguistica 64.1. 116-140. Schwarzschild, R. \& K. Wilkinson. 2002. Quantifiers in Comparatives: A Semantics of Degree Based on Intervals. Natural Language Semantics 10. 1-41. von Stechow, A. 1984. Comparing Semantic Theories of Comparison. Journal of Semantics 3.1-77. 